Acta Universitatis SaPientiae

Agriculture and Environment, 13 (2021) 23-35

DOI: 10.2478/ausae-2021-0003

\title{
Insecticide efficacy on ticks (Dermacentor spp.) - Case study from an infested territory in Transylvania, Romania
}

\author{
Artúr Botond CSORBA, ${ }^{1}$ Barna PUTNOKY-CSICSÓ, ${ }^{2}$ \\ Antal DEMETER, ${ }^{2}$ Imre-István NYÁRÁDI, ${ }^{2}$ János BÁLINT²
}

${ }^{1}$ Doctoral School in Biology and Sport Biology, University of Pécs, Faculty of Sciences Ifjúság útja 6.; e-mail: csorba.artur@ms.sapientia.ro

${ }^{2}$ Sapientia Hungarian University of Transylvania (Cluj-Napoca, Romania), Department of Horticulture, Faculty of Technical and Human Sciences, Târgu-Mureş; e-mail: balintjanos@ms.sapientia.ro

Manuscript received 12 February 2021; revised 25 March 2021; accepted 15 April 2021

\begin{abstract}
Ticks can be a major concern for humans and animals alike through the transmission of various viral and bacterial diseases. Ticks have also developed tolerance to several active compounds due to intensive insecticide treatments. The excess use of insecticides against ticks worldwide is mostly environmental contamination rather than effective control. Thus, information about the useful chemicals is essential. Dermacentor marginatus and Dermacentor reticulatus individuals were tested, being collected in Transylvania, near the city of Târgu-Mureş, Romania. The experiment was performed under laboratory conditions in two replicates, using a total of 420 ticks and 19 insecticides. The best results were achieved with alpha-cypermethrin and pyrethrin.
\end{abstract}

Keywords: infestation, tolerance, pyrethroids, organophosphates, disease

\section{Introduction}

Ticks are highly specialized, obligate, ectoparasitic arthropods [1]. Ticks feed on the blood of terrestrial mammals, birds, and reptiles, and they can introduce pathogens into the host. The adult female begins to lay eggs after several days of feeding (6-12 days). Depending on the species, it lays 1,000-18,000 eggs [2]. They can travel several kilometres on their host and can reach other continents too on migratory bird species [3].

Many new diseases are transmitted by arthropod vectors. Mosquitoes spread malaria, dengue-dengue fever, and yellow fever [4], [5], sand flies transmit 
leishmaniasis [6], ticks transmit Lyme disease, ehrlichiosis [7], [8], babesiosis, or anaplasmosis [9]. Tick-borne diseases are an important cause of losses to the livestock industry. Worldwide losses due to ticks and controlling them have been estimated at several billion dollars annually [10]. The main problem is the transmission of a wide spectrum of pathogenic microorganisms [10]. In some regions, Dermacentor spp. are important vectors of bovine anaplasmosis and babesiosis. There are several species that play an important role in human medicine as vectors of rickettsial diseases such as the European canine babesiosis [10]. The first case was reported in Croatia in 1957 [11]. The most common symptoms are high fever, headache, vomiting, and diarrhoea. Older people may also have more severe symptoms such as kidney failure and, ultimately, death [12].

Insecticide tolerance has been detected in many major vector species, and the list is constantly expanding. Resistant or tolerant populations have also been reported in several tick species [13]. Insecticide tolerance has a biochemical basis, and two main forms are known: target-site tolerance, in which case the insecticide is no longer able to bind to the binding spot because it changes, and enzyme-based (metabolic) tolerance, which occurs when oxidases or esterases show increased activity and prevent the activation of the active substances [13]. These esterases contain six families of proteins belonging to the $\alpha / \beta$-hydrolase superfamily [14]. The term multiple tolerance is used when pests can tolerate two or more insecticides with significantly different modes of action [15].

Experiments in Mexico have shown that the Rhipicephalus microplus tick has developed multiple tolerance to widely used organophosphates and pyrethroids [15]. A study in Queensland, Australia, showed that 5 treatments per season is already a risk factor for acaricide tolerance [16]. Researchers in Argentina reported similar results. Cattle ticks have developed tolerance to pyrethroids and organophosphates [17].

It is also important to mention the mode of action of insecticides. Organophosphates belonged to the first group of chemical compounds, which were also used against arachnids. They are inhibiting the enzyme acetylcholinesterase [18]. Decreases in sensitivity to the organophosphates used were recorded in the early 1950s, and today ticks have developed tolerance against 30 organophosphates in 40 countries [19]. Pyrethrins are produced from Chrysanthemum cinerariaefolium and C. coccineum, and a limitation in their application was that they decomposed to UV light and oxidation [20]. As a result, synthetic but more stable pyrethroids were produced. Their mode of action is exerted by blocking the permeability of $\mathrm{Na}^{+}$-ion channels, creating a permanent stimulus [20]. In the case of neonicotinoids, the mechanism of action is mediated by the inhibition of acetylcholine binding to the receptor [21]. Excess use of insecticide against ticks is widely practised worldwide and is mostly environmental contamination rather than effective control. Thus, information about the useful chemicals is essential to reduce environmental pollution. 
Model species: The most common species in Romania belong to the Ixodidae and Argasidae families [22]. By integrating the literature data with those derived from personal investigations, the authors present the distribution of the 27 tick species (25 ixodids and 2 argasids). In our experiment, two members of the Ixodidae family, namely Dermacentor marginatus and Dermacentor reticulatus, were used. The Eurasian Dermacentor tick species, Dermacentor marginatus (Sulzer, 1776) and Dermacentor reticulatus (Fabricius, 1794), are extremely common in Europe [23]. Dermacentor reticulatus is the second most common tick in Central Europe after Ixodes [24]. It is more present in the cooler zones. Its geographical location shows almost the same range as Dermacentor marginatus, from northern Portugal through Kazakhstan to western Siberia, but generally further north than Dermacentor marginatus [25]. In Hungary, they occur on xerophilic plants located near oak forests [26]. Dermacentor marginatus lives on steppes, alpine pastures, forest clearings, and semi-desert areas. In Germany, it particularly prefers open meadows, while in Italy it prefers open oak forests and dry meadows. It is found in the south of France from sea level up to 960 meters above sea level [27].

Objectives: Our first aim was to get a more accurate picture of the insecticide tolerance of tick populations (Dermacentor marginatus and Dermacentor reticulatus) collected from one of the most infected regions in Transylvania, near Târgu-Mureş city, Romania. We consider that the tick population from this region can reasonably characterize the potential insecticide tolerance of the entire tick population in the Carpathian Basin. The major objectives were therefore to detect the most efficient chemicals and provide an effective control method to reduce excess chemical use in the environment.

\section{Materials and methods}

\subsection{Study area}

The sampling procedure took place in an area of more than 10 hectares of agricultural land, orchards, herb, vegetable garden as well as ornamental garden, all belonging to the university campus. The area is bounded on the west by forests and is located near the main international road.

\subsection{Field collections of ticks and insecticide tolerance experiment}

The collected individuals were Dermacentor marginatus and Dermacentor reticulatus adults from different points of the infested territory. During the collection, approximately 420 individuals were collected. The GPS coordinates are $46^{\circ} 31^{\prime}$ 19.4988 " N $24^{\circ} 36^{\prime} 0.4428^{\prime \prime}$ E. The sample collection point is marked with a red arrow. 
The planned concentration for each insecticide was measured, as shown in Table 1. Two replicates were followed for each treatment. We used a total of 42 Petri dishes, two of which were used as control, where the treatment was pure water. We put randomly 10 individuals in each Petri dish and sprayed them with insecticides from the same distance. As no significant differences in mortality rate between the two species were detected, we presented the results together. Treatments were added until the substance formed a film surface on the tick bodies. This is a similar effect as when a normal in-field treatment is planned.

Table 1. Insecticides and concentration levels used in treatments

\begin{tabular}{|c|c|c|c|}
\hline Mode of action & Active substance & $\begin{array}{l}\text { Used conc. } \\
\text { mg/l } \\
\text { (act. subs.) }\end{array}$ & Commercial name \\
\hline \multirow{2}{*}{$\begin{array}{l}\text { Acetylcholinesterase } \\
\text { (AChE) inhibitors }\end{array}$} & dimethoate & & Danadim Progress \\
\hline & pirimiphos-methyl & 1,000 & Actellic 50 EC \\
\hline \multirow{4}{*}{$\begin{array}{l}\text { Sodium channel } \\
\text { modulators }\end{array}$} & alpha-cypermethrin & 50 & Fastac $10 \mathrm{EC}$ \\
\hline & delthametrin & 25 & Decis Mega 50 EW \\
\hline & lambda-cyhalothrin & 50 & Karate Zeon 50 CS \\
\hline & pyrethrin & 20 & Pestanal \\
\hline \multirow{5}{*}{$\begin{array}{l}\text { Nicotinic } \\
\text { acetylcholine receptor } \\
\text { (nAChR) competitive } \\
\text { modulators }\end{array}$} & acetamiprid & 100 & Mospilan 20 SG \\
\hline & clotiniadin & 250 & Dantop 50 WG \\
\hline & imidacloprid & 200 & Nuprid 200 SC \\
\hline & thiacloprid & 240 & Calypso 480 SC \\
\hline & thiamethoxam & 125 & Actara 25 WG \\
\hline \multirow{2}{*}{$\begin{array}{l}\text { Glutamate-gated } \\
\text { chloride channel } \\
\text { (GluCl) allosteric } \\
\text { modulators }\end{array}$} & abamectin & 9 & Vertimec $1.8 \mathrm{EC}$ \\
\hline & milbemectin & 10 & Milbeknock EC \\
\hline $\begin{array}{l}\text { Voltage-dependent } \\
\text { sodium channel } \\
\text { blockers }\end{array}$ & indoxacarb & 150 & Steward $30 \mathrm{DF}$ \\
\hline $\begin{array}{l}\text { Mite growth inhibitors } \\
\text { affecting CHS1 }\end{array}$ & hexythiazox & 50 & Nissorun $10 \mathrm{WP}$ \\
\hline $\begin{array}{l}\text { Mitochondrial } \\
\text { complex III electron } \\
\text { transport inhibitors }\end{array}$ & bifenazate & 120 & Floramite 240 SC \\
\hline \multirow{3}{*}{$\begin{array}{l}\text { Mitochondrial } \\
\text { complex I electron } \\
\text { transport inhibitors }\end{array}$} & fenazaquin & 200 & Magus 200 SC \\
\hline & fenpyroximate & 100 & Ortus $5 \mathrm{SC}$ \\
\hline & pyridaben & 300 & Sanmite $20 \mathrm{WP}$ \\
\hline
\end{tabular}


One minute after the treatment, the individuals were examined separately, and this was repeated in every 15 minutes for one hour, and after that in every hour. Observations were made once after 24 hours and again after 1 week. It was previously detected concerning this mechanism that the gnathostome remained open in a V-shaped form for all dead individuals in all cases. We believe that this can be a method to detect mortality; however, no parallel action was detected for these individuals either - they all were considered dead.

\subsection{Data analysis}

Data were analysed with PASW Statistics 18, release version 18.0.0 (29 June 2012). The original data normality was not met; therefore, the non-parametric Mann-Whitney U tests was used to compare the treatments. Means with different letters in diagrams represent statistically significant differences. Values were considered to be significantly different at $\mathrm{p}<0.05$.

\section{Results and discussions}

\subsection{Efficacy of pyrethroids}

The treatment with the natural pyrethrin had an effective knock-down effect against ticks (Figure 1). After one minute, 30\% of the individuals were dead, and after 15 minutes the mortality rate reached over $80 \%$.

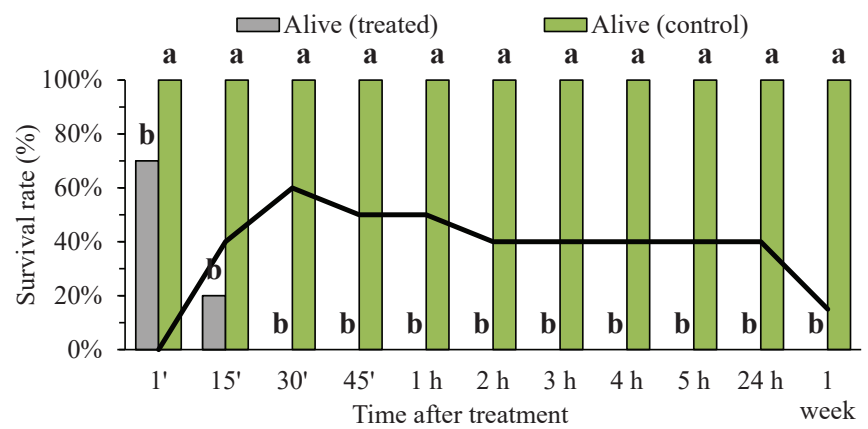

Note: the different letters mean statistically significant differences.

Figure 1. Efficacy of pyrethrin on tick adults (Mann-Whitney test: $p<0.05$ )

The best effect was obtained with alpha-cypermethrin (Figure 2), which killed all individuals after 30 minutes. Deltamethrin and lambda-cyhalothrin treatment produced similarly good results; after 1 hour, the mortality rate was $100 \%$. 


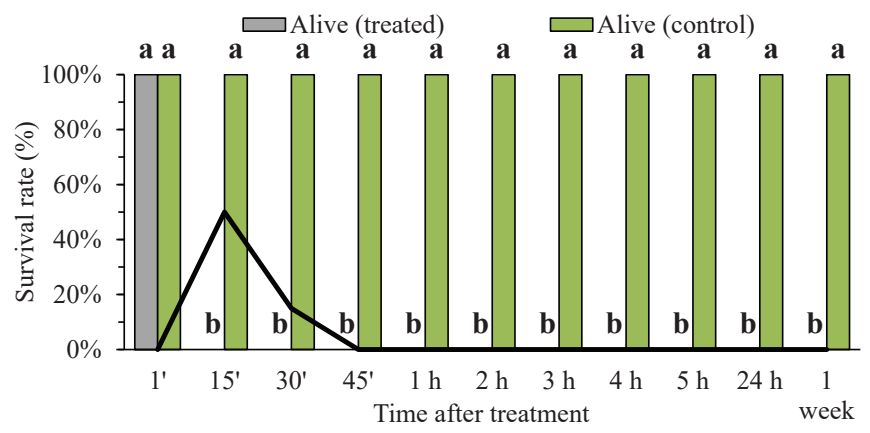

Note: the different letters mean statistically significant differences.

Figure 2. Efficacy of alpha-cypermethrin on tick adults

(Mann-Whitney test: $\mathrm{p}<0.05$ )

\subsection{Efficacy of organophosphates}

Significant difference was found between pirimiphos-methyl treatment and the control (Figure 3). After 3 hours, 10\% of the individuals were dead, in 4 hours the mortality rate reached $20 \%$, and after 5 hours half of the adults were dead. 24 hours after the application of insecticides, the mortality rate was $80 \%$ and $20 \%$ of the individuals showed weak signs of life. After 1 week, the mortality rate reached $100 \%$. The treatment with dimethoate yielded similar results, with the difference that the first individuals died just after $24 \mathrm{hrs}$, and no live individuals were found after 1 week.

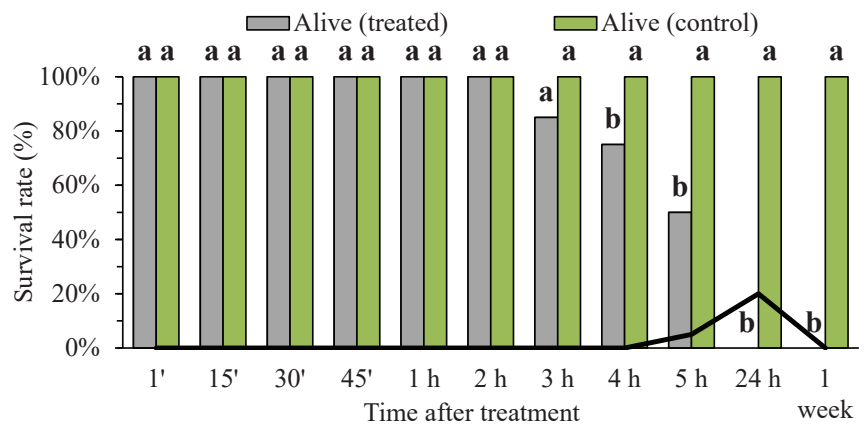

Note: the different letters mean statistically significant differences.

Figure 3. Efficacy of pirimiphos-methyl on tick adults

(Mann-Whitney test: $\mathrm{p}<0.05$ ) 


\subsection{Efficacy of neonicotinoids}

Imidacloprid and acetamiprid had no effect on ticks, all individuals were alive after one week. The active substance clothianidin was also ineffective against ticks - after 1 week, a single death was observed. The third member in this chemical group was thiamethoxam, which proved to be completely ineffective, and no dead individuals were found after 1 week, and the last member of the group was thiacloprid. In this one case, the treatment was effective against ticks (Figure 4). After 1 hour of treatment, $100 \%$ of the individuals showed weak signs of life, and after 1 week the mortality rate reached $20 \%$.

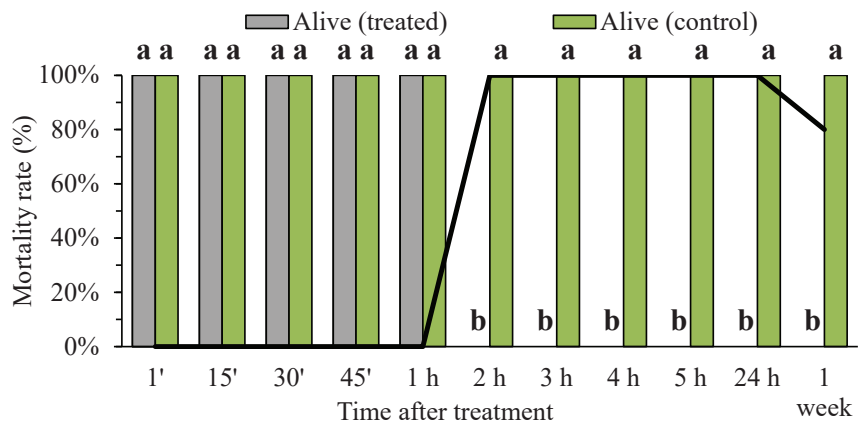

Note: the different letters mean statistically significant differences.

Figure 4. Efficacy of thiacloprid on tick adults (Mann-Whitney test: $\mathrm{p}<0.05$ )

\subsection{The efficacy of avermectins}

Both abamectin and milbemectin treatments have been shown to be ineffective against ticks. In the case of abamectin treatment, all individuals were alive after 1 week, and in the case of milbemectin treatment, the mortality rate was around $10 \%$ after 1 week.

\subsection{The efficacy of acaricides}

The acaricides used in the experiment were not effective enough either. The active substances fenazaquin and hexithiazox were ineffective on ticks, and we did not find any dead individual after 1 week. The treatment with piridaben was not effective, as the individuals were alive after a week. In the case of bifenazate and fenpyroximate (Figure 5) treatments, dead individuals were found after 24 hours, but the mortality rate was around $60 \%$, and all of the individuals died just after a week. 


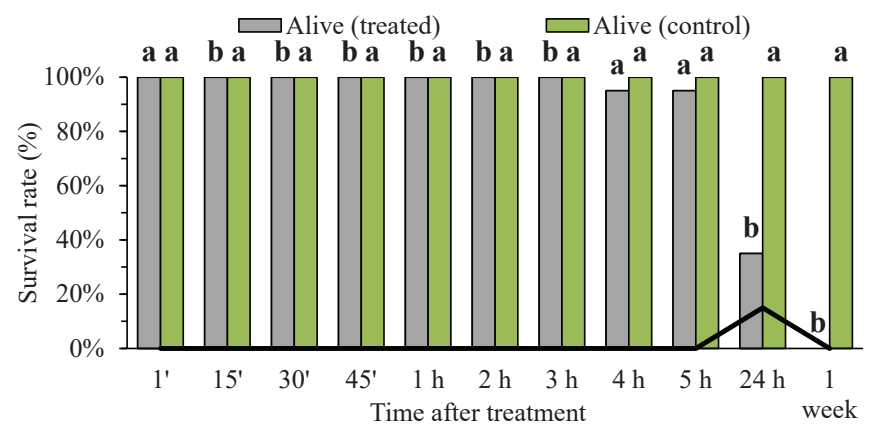

Note: the different letters mean statistically significant differences.

Figure 5. Efficacy of fenpyroximate on tick adults (Mann-Whitney test: $\mathrm{p}<0.05$ )

\subsection{The efficacy of oxadiazine}

The treatment with indoxacarb had no effect against ticks: the mortality rate remained $0 \%$ after a week.

Tick control in the infected area has been performed with pirimiphos-methyl for the last 3 years. In the first two years, population control was relatively successful, but in the third year the treatment proved unsuccessful, so we decided to collect individuals and investigate the effects of marketed insecticides on the collected individuals. According to these, a specific substance commercialized against ticks (pirimiphos-methyl) was less effective with time, generating a low mortality rate of ticks. As several other insecticides are commercialized as having acaricide effects too, and other acaricides might also have weaker effect, testing these substances to give a clear picture about their effects is extremely important.

Previous similar studies from Mexico and Argentina indicated that natural populations of Rhipicephalus microplus (Canestrini, 1888) were found to be tolerant to a number of pyrethroids [15], [17]. Another study from Brazil showed that 578 tick larvae were tested for pyrethroids, and $97.44 \%$ of them were tolerant to the treatment [18]. However, in our region, we got the best results with pyrethroids. Alpha-cypermethrin and pyrethrin (after $1 \mathrm{~h}$ : 100\% death or weak signs of life) yielded the best results. $80 \%$ of the individuals died after the pyrethrin treatment within 15 minutes. We found significant differences between the treatments and the control. The mortality rate reached 100\% after 15 minutes with the alphacypermethrin treatment. Deltamethrin also had a good effect because all the ticks were dead after 1 hour of the application.

In the case of organophosphates, there are several studies where the tolerance has been well described. Two different strains of Bophilus were used in the U.S.A. [28]. In the first case, a large number of female adults survived the dip treatment and produced viable offspring. In the second case, similar results were obtained, 
but the tolerance ratio was higher, and the female adults were able to produce viable offspring [28]. The treatments with dimethoate were not effective because the individuals were dead just after 1 day of treatment. In the case of pirimiphosmethyl, 10\% of the individuals were dead after 3 hours, the mortality rate reached $20 \%$ in 4 hours, and half of the adults were dead after 5 hours. After 24 hours, the mortality rate was $80 \%$, and $20 \%$ of the individuals showed weak signs of life.

After nearly two decades of use, several target pests of neonicotinoids have begun to develop tolerance [29]. In our experiment, the treatments with neonicotinoids, with the exception of clothianidin, were totally ineffective against the ticks. The mortality rate was near $60 \%$ upon the clothianidin treatment, but only after 1 week of the treatment.

Because of the intensive use of the macrocyclic lactones, partial tolerance has been reported in $R$. microplus in different regions [30]. The exact mechanism is still unknown, but some studies [31] concluded that tolerance in ticks might be due to target-site insensitivity. We obtained almost the same results in our experiment. The avermectins (abamectin, milbemectin) were ineffective because $100 \%$ of the individuals were alive after one day of the application.

In the European Union, indoxacarb is approved as a topical spot-on flea control product for dogs and cats, and, in combination with permethrin, as a topical spot-on flea and tick control for dogs [32]. In our experiment, we used Steward $30 \mathrm{DF}$ with indoxacarb as active compound, but it had no effect against ticks - the mortality rate remained $0 \%$ after a week.

As ticks age, they become increasingly susceptible to acaricides [33]. But populations of several tick species in tropical and subtropical countries have developed high tolerance to compounds due to the high intensity of their use in tick management [34], [35]. The treatments with acaricides contradicted our expectations. Among these, fenpyroximate killed $50 \%$ of the individuals, but only 1 day after the treatment; the other compounds were ineffective, and the ticks were highly tolerant to treatments.

Altogether, the tolerance mechanisms seem to have both a genetic and a behavioural background. From a genetic point of view, ticks can develop a tolerance if a compound is widely used, and these mechanisms can be passed on to the next generations too.

From a behavioural point of view (which can be in fact combined with genetic tolerance as well), ticks can move or can be moved artificially and/or accidentally between regions. Several populations with different genetic backgrounds can be mixed in this way, increasing tolerance mechanisms and their spread in the population. Considering these effects, a continuous test of commercialized insecticides and acaricides needs to be made periodically.

Insecticides that showed an effect only after 24 hours or a few days did not prove to be effective because we cannot produce this maximum contact effect 
under natural conditions but only under laboratory conditions. These wisely used chemicals are not recommended against ticks, as it will only result in high levels of environmental contamination.

Based on our results, the treatments with alpha-cypermethrin, pyrethrin, and other pyrethroids could have a good effect against Dermacentor species. We do not recommend other chemicals for tick control.

\section{Conclusions}

In conclusion, Dermancentor marginatus and Dermancentor reticulatus species collected from the campus of Sapientia Hungarian University of Transylvania showed a high degree of tolerance to the majority of the 19 insecticides we tested. Considering the treatments, we can conclude that pyrethroid treatments (alphacypermethrin, deltamethrin, lambda-cyhalothrin, pyrethrin) were effective against ticks, whereas neonicotinoids, avermectins, and even acaricide treatments were almost completely ineffective. The desired effect was not achieved with the organophosphates either, so it can be concluded that the two Dermacentor species involved in the treatments have developed a high degree of tolerance in recent years. We should mention the importance of insecticide rotation, more likely the usage of insecticides with different modes of action to reduce and slow down tolerance development and reduce excessive chemical use.

\section{Acknowledgments}

This work was supported by Sapientia Hungarian University of Transylvania, Faculty of Technical and Human Sciences. The authors would like to express their special thanks to Csaba Miklós and Róbert Koncz for their assistance provided in the collection of the individuals and for their help in the experiment.

\section{References}

[1] Anderson, J. F., Magnarelli, L. A. (2008), Biology of ticks. Infectious Disease Clinics of North America 22(2), 195-215. DOI: 10.1016/j.idc.2007.12.006.

[2] Ginsberg, H. S., Stafford, K. C. (2014), Management of ticks and tick-borne diseases. In: Goodman, J. L., Dennis, D. T., Sonenshine, D. E. (eds.), Tickborne diseases of humans. Washington, DC, USA: ASM Press. 65-86. DOI: 10.1128/9781555816490.ch4.

[3] Service, M. W. (2012), Medical entomology for students, $5^{\text {th }}$ ed. Cambridge: Cambridge University Press. 
[4] Krostad, D. J. (1996), Malaria as a reemerging disease. Epidemiologic Reviews 18(1), 77-89. DOI: 10.1093/oxfordjournals.epirev.a017918.

[5] Gubler, D. J., Clark, G. G. (1995), Dengue/dengue hemorrhagic fever: The emergence of a global health problem. Emerging Infectious Diseases 1(2), 55-57. DOI: 10.3201/eid0102.952004.

[6] Meslin, F.-X. (1997), Global aspects of emerging and potential zoonoses: A WHO perspective. Emerging Infectious Diseases 3(2), 223-228. DOI: 10.3201/eid0302.970220.

[7] Daniels, T. (1997), Deer ticks (Ixodes scapularis) and the agents of lyme disease and human granulocytic ehrlichiosis in a New York city park. Emerging Infectious Diseases 3(3), 353-355. DOI: 10.3201/eid0303.970312.

[8] Walker, D. H., Dumler, J. S. (1996), Emergence of the ehrlichioses as human health problems. Emerging Infectious Diseases 2(1), 18-29. DOI: 10.3201/ eid0201.960102.

[9] Alim, A., Das, S., Roy, K., Sikder, M. S., Hassan, M. M., Siddiki, A. Z., Hossain, M. A. et al. (2012), Prevalence of hemoprotozoan diseases in cattle population of Chittagong division, Bangladesh. Pakistan Veterinary Journal 32(2): 221-224.

[10] Jongejan, F., Uilenberg, G. (1994), Ticks and control methods: -EN- -FR- -ES-. Rev. Sci. Tech. OIE 13(4), 1201-1226. DOI: 10.20506/rst.13.4.818.

[11] Skrabalo, Z., Deanovic, Z. (1957), Piroplasmosis in man; report of a case. Doc. Med. Geogr. Trop. 9(1), 11-16.

[12] Kjemtrup, A. M., Conrad, P. A. (2000), Human babesiosis: Sn emerging tickborne disease. International Journal for Parasitology 30(12-13), 1323-1337. DOI: 10.1016/S0020-7519(00)00137-5.

[13] Brogdon, W. G., McAllister, J. C. (1999), Insecticide resistance and vector control. Journal of Agromedicine 6(2), 41-58. DOI: 10.1300/J096v06n02_04.

[14] Cygler, M. et al. (1993), Relationship between sequence conservation and three-dimensional structure in a large family of esterases, lipases, and related proteins. Protein Science 2(3), 366-382. DOI: 10.1002/pro.5560020309.

[15] Foil, L. D. et al. (2004), Factors that influence the prevalence of acaricide resistance and tick-borne diseases. Veterinary Parasitology 125(1-2), 163-181. DOI: 10.1016/j.vetpar.2004.05.012.

[16] Jonsson, N. N., Mayer, D. G., Green, P. E. (2000), Possible risk factors on Queensland dairy farms for acaricide resistance in cattle tick (Boophilus microplus). Veterinary Parasitology 88(1-2), 79-92. DOI: 10.1016/S03044017(99)00189-2.

[17] Mangold, A. J., Castelli, M. E., Nava, S., Aguirre, D. H., Guglielmonechi, A. A. (2005), Poblaciones de la Garrapata Rhipicephalus (Boophilus) Microplus Resistentes a los Piretroides en Córdoba y Salta, Argentina. FAVE Cs Vet 3(1-2), 55-59. DOI: 10.14409/favecv.v3i1/2.1405. 
[18] Faza, A. P. et al. (2013), A new approach to characterization of the resistance of populations of Rhipicephalus microplus (Acari: Ixodidae) to organophosphate and pyrethroid in the state of Minas Gerais, Brazil. Experimental Parasitology 134(4), 519-523. DOI: 10.1016/j.exppara.2013.04.006.

[19] Van Leeuwen, T. Vontas, J., Tsagkarakou, A., Dermauw, W., Tirry, L. (2010), Acaricide resistance mechanisms in the two-spotted spider mite Tetranychus urticae and other important Acari: A review. Insect Biochemistry and Molecular Biology 40(8), 563-572. DOI: 10.1016/j.ibmb.2010.05.008.

[20] Weston, D. P. et al. (2013), Multiple origins of pyrethroid insecticide resistance across the species complex of a nontarget aquatic crustacean, Hyalella azteca. Proceedings of the National Academy of Sciences 110(41), 16532-16537. DOI: 10.1073/pnas.1302023110.

[21] Ábrahám, R., Érsek, T., Kuroli, G., Németh, L., Reisinger, P. (2011), Növényvédelem. Debreceni Egyetem, Nyugat Magyarországi Egyetem, Pannon Egyetem.

[22] Coipan, E., Vladimirescu, A., Ciolpan, O., Teodorescu, I. (2011), Tick species (Acari: Ixodoidea) distribution, seasonality and host associations in Romania. Travaux du Muséum National d'Histoire Naturelle "Grigore Antipa” 54(2), 301-317. DOI: 10.2478/v10191-011-0018-y.

[23] Rubel, F. et al. (2016), Geographical distribution of Dermacentor marginatus and Dermacentor reticulatus in Europe. Ticks and Tick-borne Diseases 7(1), 224-233. DOI: 10.1016/j.ttbdis.2015.10.015.

[24] Rubel, F. et al. (2014), The first German map of georeferenced ixodid tick locations. Parasites Vectors 7(1), 477. DOI: 10.1186/s13071-014-0477-7.

[25] Rar, V. A. et al. (2005), Tickborne pathogen detection, Western Siberia, Russia. Emerging Infectious Diseases 11(11), 1708-1715. DOI: 10.3201/ eid1111.041195.

[26] Hornok, S., Farkas, R. (2009), Influence of biotope on the distribution and peak activity of questing ixodid ticks in Hungary. Medical and Veterinary Entomology 23(1), 41-46. DOI: 10.1111/j.1365-2915.2008.00768.x.

[27] Bonnet, S. et al. (2013), Prevalence of tick-borne pathogens in adult Dermacentor spp. ticks from nine collection sites in France. Vector-Borne and Zoonotic Diseases 13(4), 226-236. DOI: 10.1089/vbz.2011.0933.

[28] Temeyer, K. B. et al. (2004), Organophosphate resistance in Mexican strains of Boophilus microplus: A major threat to the U.S. cattle industry. SAAS Bulletin: Biochemistry and Biotechnology. Accessed on: 15 October 2020. [Online]. Available at: https://agris.fao.org/agris-search/search. do?recordID=US201301003885.

[29] Jeschke, P., Nauen, R., Schindler, M., Elbert, A. (2011), Overview of the status and global strategy for neonicotinoids. Journal of Agricultural and Food Chemistry 59(7), 2897-2908. DOI: 10.1021/jf101303g. 
[30] Martins, J. R., Furlong, J. (2001), Avermectin resistance of the cattle tick Boophilus microplus in Brazil. Veterinary Record 149(2), 64.

[31] Lovis, L., Reggi, J., Berggoetz, M., Betschart, B., Sager, H. (2013), Determination of Acaricide resistance in Rhipicephalus (Boophilus) microplus (Acari: Ixodidae) field populations of Argentina, South Africa, and Australia with the larval tarsal test. Jnl. Med. Entom. 50(2), 326-335. DOI: 10.1603/ME12127.

[32] Gwaltney-Brant, S. M. (2013), Atypical topical spot-on products. Small Animal Toxicology. Elsevier. 741-754. DOI: 10.1016/B978-1-4557-07171.00070-3.

[33] Mount, G. A., Lofgren, C. S., Pierce, N. W. (1970), Effect of age on the susceptibility of nymphs of the lone star tick to insecticides. Journal of Economic Entomology 63(5), 1681-1682. DOI: 10.1093/jee/63.5.1681.

[34] Rodríguez-Vivas, R. I., Rodríguez-Arevalo, F., Alonso-Díaz, M. A., FragosoSanchez, H., Santamaria, V. M., Rosario-Cruz, R. (2006), Prevalence and potential risk factors for amitraz resistance in Boophilus microplus ticks in cattle farms in the State of Yucatan, Mexico. Preventive Veterinary Medicine 75(3-4), 280-286. DOI: 10.1016/j.prevetmed.2006.04.001.

[35] Perez-Cogollo, L. C., Rodriguez-Vivas, R. I., Ramirez-Cruz, G. T., Miller, R. J. (2010), First report of the cattle tick Rhipicephalus microplus resistant to ivermectin in Mexico. Veterinary Parasitology 168(1-2), 165-169. DOI: 10.1016/j.vetpar.2009.10.021. 